\title{
DYNAMIC DAYLIGHT AND SOLAR CONTROL IN TROPICAL CLIMATE
}

\author{
Yaik-Wah Lim \\ Department of Architecture, Faculty of Built Environment, Universiti Teknologi Malaysia, Malaysia
}

Received 2013-08-24; Revised 2014-04-27; Accepted 2014-10-10

\begin{abstract}
Daylight is dynamic, thus there is no one common solution for all scenarios. It is more critical in tropical climate where the sky is predominantly intermediate; with inconsistent clouds formations which will influence the presence of direct sunlight and daylight availability. In this study, the potential of dynamic internal shading devices for improving daylighting performances in tropical climate was investigated. Scaled physical models and computer simulation methods were employed to examine daylighting performances of various internal shading devices under different tropical sky conditions: Intermediate sky with direct sunlight, Intermediate sky without direct sunlight and Overcast sky. The findings proved that the shading devices yielded significant different performances under various sky conditions. The effective daylighting depth under tropical sky can be as deep as 3.8 times height of the window from work plane. Dynamic internal shading device was suggested for effective daylighting in the tropics.
\end{abstract}

Keywords: Light Shelf, Visual Comfort, Physical Model, Simulation, Tropical Sky

\section{INTRODUCTION}

Daylighting has been proven as an effective strategy to provide energy saving as well as visual comfort for the users. In tropical climate, global illuminance can go as high as 120,000 lx. Yet, previous research concluded that the abundance of tropical daylight has not been utilized to the maximum since it is usually concurrent with intense solar heat gain (Lim, 2013; Lim et al., 2013). The balance between the prevention of heat gains and daylight penetration is very crucial in order to achieve building energy efficiency. Thus daylight and solar control for energy saving and visual comfort in tropical climate needs to be further investigated.

According to Ahmed et al. (2002), the monthly average Nebulosity Index (NI) of the sky at Subang, West Malaysia indicates that $85.6 \%$ of the time the sky was predominantly intermediate, $14.0 \%$ overcast and $0 \%$ blue. Djamila et al. (2011) further studied the sky condition at Kota Kinabalu, East Malaysia using both NI and sky ratio. The results showed $70-90 \%$ of the sky was intermediate using cloud cover ratio; $100 \%$ of the sky was predominantly intermediate for the whole year using NI method. All of the previous research concluded that tropical sky is predominantly intermediate, which has inconsistent clouds formations that influence the presence of Direct Sunlight (DSL) and daylight availability. Thereby dynamic daylight and solar control is an important approach to optimise tropical daylighting.

\section{MATERIALS AND METHODS}

To study daylighting performances of shading device under various tropical sky conditions, simulating the sky is very critical to assure the reliability of results. Physical model is suitable to achieve the objective of study. Light behaves in the same way in a scaled model as it does in a full-scale building. Scaled models had been widely used for daylighting research (Egan and Olgyay, 2002; Lim et al., 2010). Thereby this study employed both scaled physical model and computer simulation methods for comparison and validation.

As shown in Fig. 1, two scaled physcial models (1:20) were constructed ( 1 as base case; 1 with internal light shelf) 
in order to test daylight penetration patterns of various internal light shelves under actual tropical sky conditions. These models represented high-rise open plan offices within the typical $8.4 \times 8.4 \mathrm{~m}$ structural grid. These models had Window-to-Wall Ratio (WWR) of $70.4 \%$. Table 1 indicates the models internal surfaces reflectance values.

The measurement was conducted at an open area in Johor Bahru, Malaysia (Latitude 1 ${ }^{\circ} 33^{\prime} \mathrm{N}$ and Longitude $103^{\circ} 37^{\prime}$ E). The models were located at the area without any shading from the adjacent building or vegetation. Both of the models were tested concurrently in this experiment. The Base Case model was used as a reference to compare with the model with internal light shelf. There were total of 4 internal light shelves configurations experimented using the physical scaled model (Fig. 2).

One illuminance meter Delta OHM LP-PHOT 02, Probe E (PE) with data logger was installed on the top of the models to measure global illuminance, $\mathrm{E}_{\mathrm{G}}$. The measurement range of the equipment was 0-150 klx. Concurrently, 4 illuminance meters Delta OHM LPPHOT 01 with data loggers, Probe 1 (P1) and Probe 2 (P2) were installed inside the Base Case model; while Probe 3 (P3) and Probe 4 (P4) were installed inside the model with internal light shelf, to measure internal absolute Work Plane Illuminance (WPI).

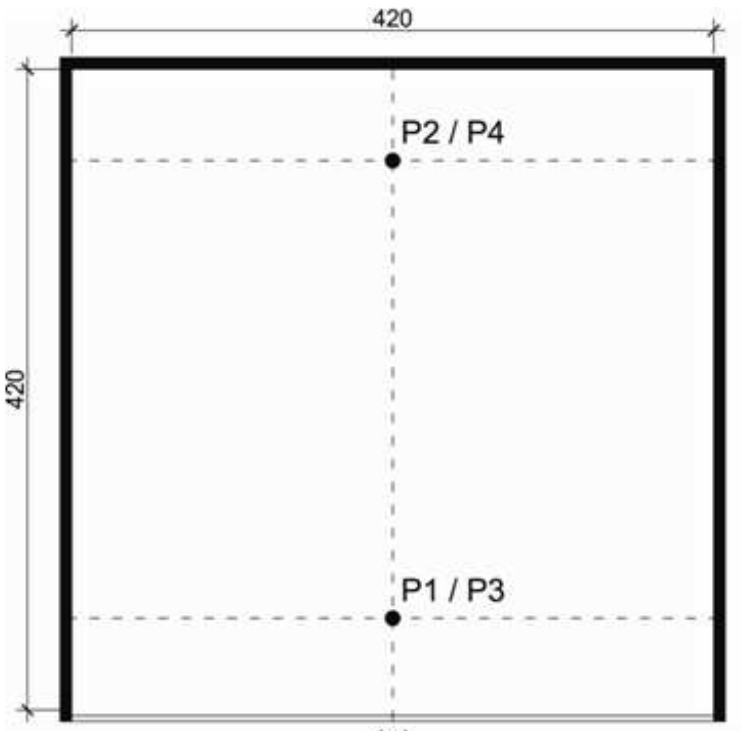

(a)

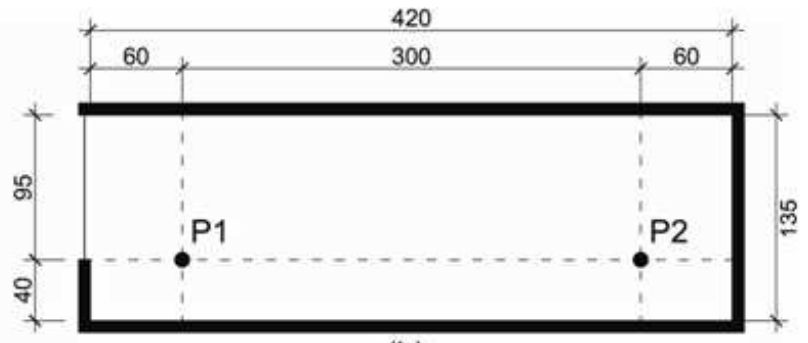

(b)

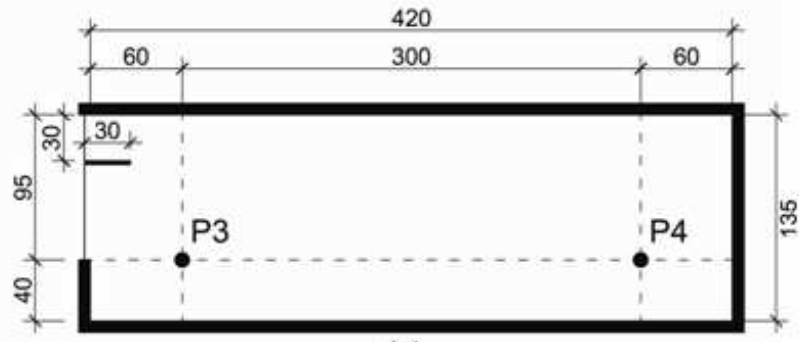

(c)

Fig. 1. Configuration of the physical model with scale 1:20: (a) Plan; (b) Section of base case model; (c) Section of model with light shelf
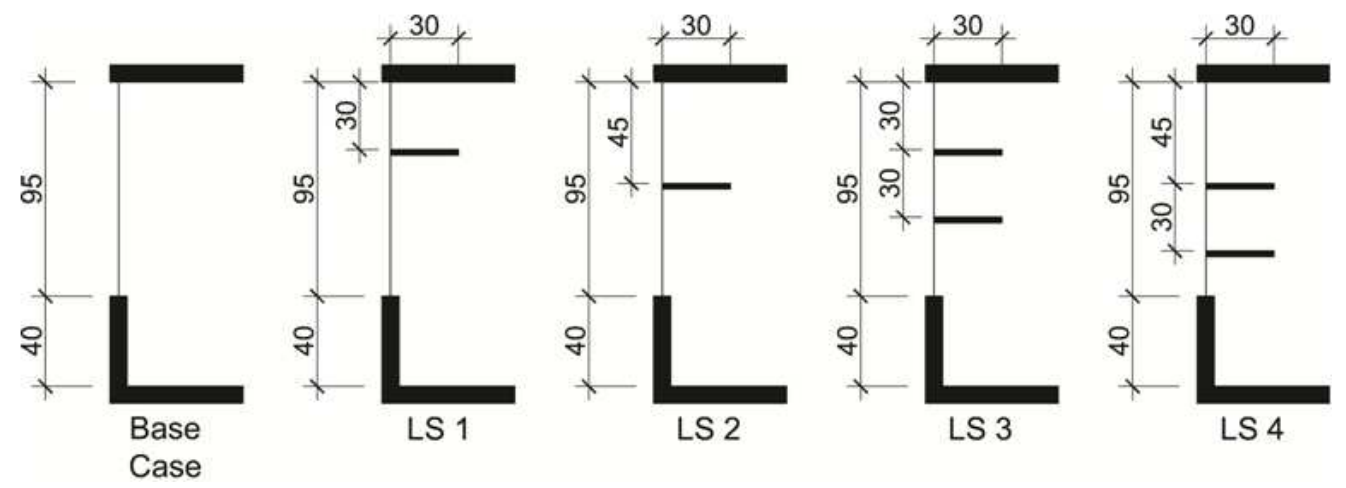

Fig. 2. Configurations of base case and various internal light shelves (LS 1 to 4) with scale 1:20 
Table 1. Internal surfaces reflectance

\begin{tabular}{lc}
\hline Surface & Reflectance value (\%) \\
\hline Wall & 57.26 \\
Ceiling & 61.73 \\
Floor & 16.78 \\
Light shelf (aluminum) & 51.29 \\
\hline
\end{tabular}

Table 2. Summary of measurement data selected for analysis

\begin{tabular}{lllll}
\hline Date & Time & Orientation & Sky condition & DSL \\
\hline 6 Mar 12 & $12.15-12.30 \mathrm{~h}$ & North & Intermediate & $\mathrm{X}$ \\
7 Mar 12 & $09.15-09.30 \mathrm{~h}$ & East & Intermediate & $\sqrt{ }$ \\
8 Mar 12 & $15.00-15.15 \mathrm{~h}$ & West & Intermediate & $\sqrt{ }$ \\
9 Mar 12 & $11.45-12.00 \mathrm{~h}$ & South & Overcast & $\mathrm{X}$ \\
\hline
\end{tabular}

Prior to the measurement, all the illuminance meters were calibrated. During the measurement, the sky conditions were observed. All the measurements were taken during 1-9 March 2012, with intervals of $30 \mathrm{sec}$. However, only certain data were selected for analysis in order to investigate the daylighting performances under different sky conditions as summarised in Table 2.

This study also employed Radiance-based computer simulation to compare with the field measurement results. Radiance is developed by Greg Ward at Lawrence Berkeley National Laboratories, widely recognised and validated by the lighting professionals (Reinhart and Fitz, 2006; Lim et al., 2010). Models with configurations and surface reflectivity exactly the same as the scaled physical models were constructed in the simulation tool. Besides, the sky conditions, dates and times for the simulations were also the same as the measurement as stated in Table 2.

Previous research demonstrated that the application of CIE (International Commission on Illumination) skies to simulate tropical daylighting will result in underestimation of absolute daylight level (Lim et al., 2012). This is because the external illuminance in the tropics can be as high as $130 \mathrm{klx}$ while the simulation with CIE skies gives external illuminance below $20 \mathrm{klx}$. Thus employing relative ratios is more reliable in comparison with the absolute values.

Both the measurement and simulation datas were then analysed to study the relative Daylight Ratio (DR) for intermediate sky or Daylight Factor (DF) for overcast sky (Equation 1). DR and DF for different glazing types were computed by multiplying the measured results with respective Visible Transmittance (VT) as shown in Equation 2. Three types of glazing were tested: (1) Clear glazing with VT 75\%; (2) Tinted glazing with VT 50\%; and (3) Reflective glazing with VT 25\%:

$$
\begin{aligned}
& D R \text { or } D F=W P I_{\text {internal }} / E_{G} \times 100 \% \\
& D R_{\text {with glazing }}=D R_{\text {without glazing }} \times V T_{\text {selected glazing }}
\end{aligned}
$$

\section{RESULT}

The average global illuminance, $\mathrm{E}_{\mathrm{G}}$ measured during various sky conditions and simulated using CIE skies are as shown in Fig. 3. The measurements showed that under intermediate sky at noon time (12.15-12.30 h), the average $E_{G}$ was as high as $81.26 \mathrm{klx}$. During intermediate sky in the morning and afternoon, the average $\mathrm{E}_{\mathrm{G}}$ was $40-50 \mathrm{klx}$. Even during the overcast sky, the average $E_{G}$ still reached $27.81 \mathrm{klx}$. Subsequently, assumptions were made in this study by taking the average $\mathrm{E}_{\mathrm{G}}$ of $80 \mathrm{klx}$ for intermediate sky at noon (without DSL), 40 klx for intermediate sky in the morning and afternoon (with DSL) and $20 \mathrm{klx}$ for overcast sky. However, the simulated $\mathrm{E}_{\mathrm{G}}$ employing CIE skies was below $20 \mathrm{klx}$ during all the sky conditions. Therefore, the simulated internal absolute WPI could not be directly employed for analysis. The simulation results were converted to DR for comparison against the measurement results.

The DR under intermediate sky with DSL from east orientation (in the morning) was much higher compared with DR under other sky conditions. As shown in Fig. 4a, Base Case yielded DR of $68.95,45.97$ and $22.98 \%$ at P1, for VT 75, 50 and 25\% respectively. LS 1, LS 2, LS 3 and LS 4 successfully reduced WPI at P3 while increased WPI at P4. This proved that the internal light shelf reflected DSL to the deeper area of the office room. With the assumption of $40 \mathrm{klx} \mathrm{E}_{\mathrm{G}}$ during intermediate sky in the morning, only LS 4 managed to reduce the extremely high DR to below $2000 \mathrm{~lx}$ at P3 while still maintaining WPI of $500 \mathrm{~lx}$ at P4 with VT 25\%. Simulation demonstrated similar results with the measurement except for LS 2. This was due to DSL patch felt on P3 in the daylight simulation.

Figure $4 \mathbf{b}$ indicates DR for all the test cases under intermediate sky without DSL, with different VT. The result showed that for a full-glazed office room under tropical sky, the indoor daylight level was extremely high. Even with reflective glazing, the WPI level was about $1872 \mathrm{~lx}$ with the assumption of $80 \mathrm{klx} \mathrm{E}_{\mathrm{G}}$. LS 4 successfully reduced the DR at P3 to $2.50 \%$ even with clear glazing. When reflective glazing was used, all the cases had WPI at P2 or P4 lower than the recommended minimum $300 \mathrm{~lx}$ (DSM, 2007). In general, all the simulated results were lower than the measured results except for LS 1. The simulation results showed that LS 4 caused DR as low as $0.10 \%$ at P4 even with VT $50 \%$. 
Yaik-Wah Lim / American Journal of Applied Sciences 11 (10): 1766-1772, 2014

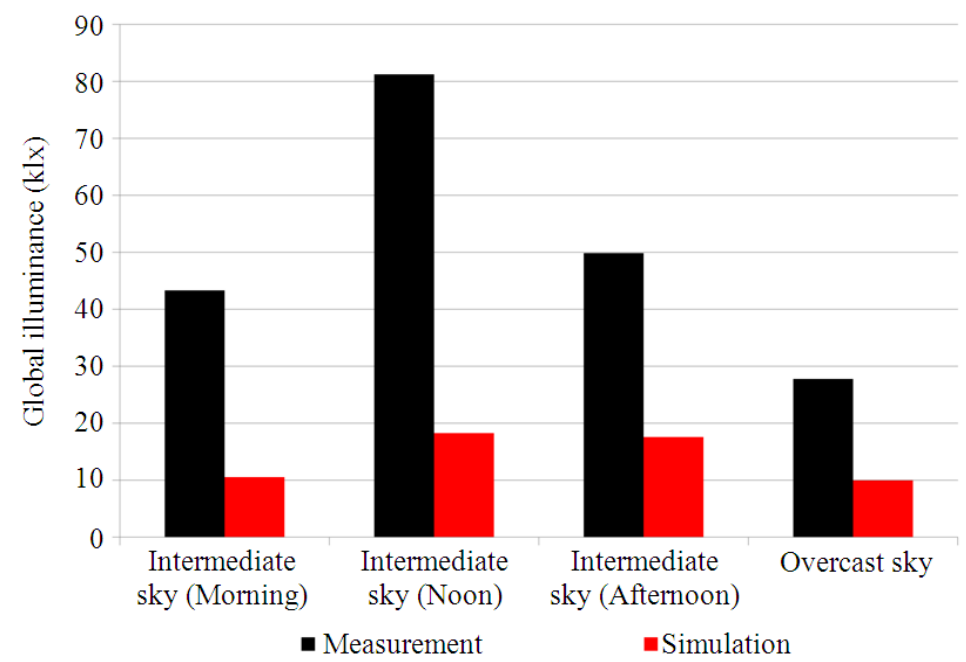

Fig. 3. Average measured and simulated global illuminance, $E_{\mathrm{G}}(\mathrm{klx})$ during various sky conditions

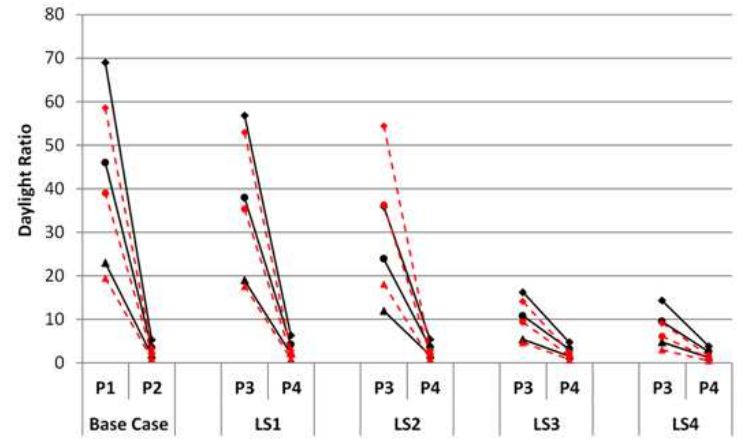

(a)

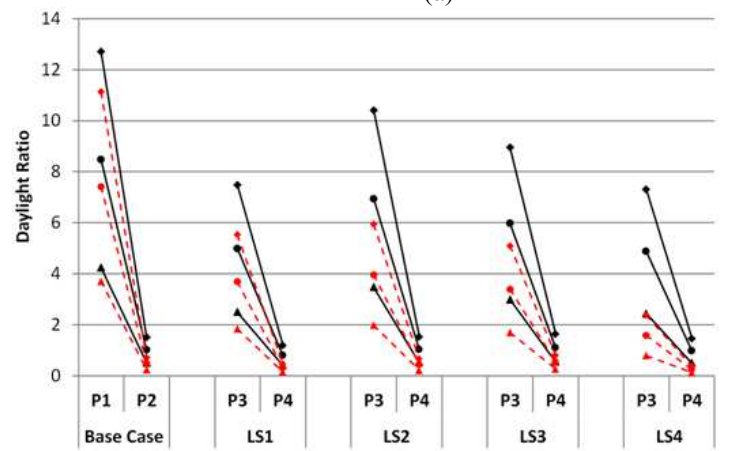

(c)

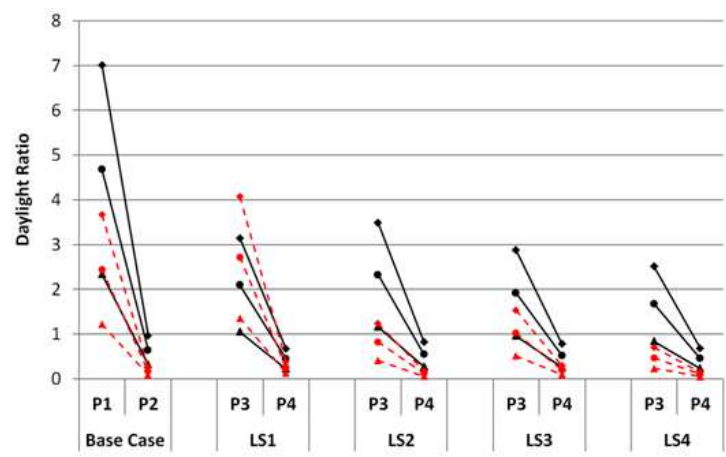

(b)

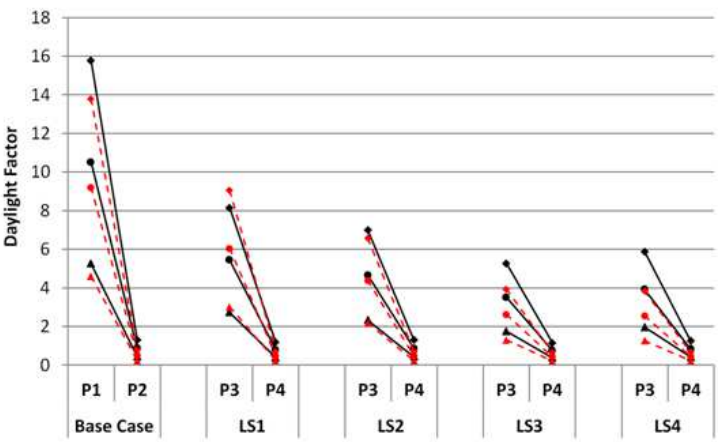

(d)

\section{$\rightarrow$ Measurement VT 75\% $\quad-$ Measurement VT 50\% $\quad$-Measurement VT 25\% \\ $\rightarrow$ Simulation VT 75\% $\quad \rightarrow$ Simulation VT $50 \% \quad \rightarrow$ Simulation VT $25 \%$}

Fig. 4. Measured and Simulated DR or DF for various test cases under different tropical sky conditions (a) Intermediate sky with DSL (Morning) (b) intermediate sky without DSL (Noon) (c) intermediate sky with DSL (Afternoon) (d) overcast sky 
Figure 4c shows that DR for test cases under intermediate sky with DSL from west orientation was lower in comparison with test cases facing east orientation. This can be due to the different solar angles during the morning and afternoon. Among all the test cases, LS 1 and LS 4 gave the lowest DR, reducing the ratio at $\mathrm{P} 3$ to below $7.50 \%$ even with clear glazing. On the other hand, LS 3 managed to maintain the lowest DR at $0.55 \%(\mathrm{P} 4$ with VT $25 \%)$ while decreasing the highest DR to $8.95 \%$ (P3 with VT $75 \%$ ). The simulation yielded lower DR than the measurement for all the test cases.

Under overcast sky, the highest DF for Base Case was $15.76 \%$ at P1 with VT $75 \%$ (Fig. 4d). This indicated that the Base Case office room with bared window and clear glazing was not suitable for tropical daylighting because even during the overcast sky the indoor WPI (approximately 3148 lx) was still too high with thermal and glare problems. LS 2 showed the most promising results by lowering the DF at P3 with clear glazing to $6.98 \%$ while still allowing DF $0.43 \%$ at $\mathrm{P} 4$ with reflective glazing. The daylight simulation gave similar results in comparison with the measurement. This proved that the simulation using CIE overcast sky was able to estimate the actual daylight performance under real overcast sky conditions.

\section{DISCUSSION}

The comparison of measurement results against the simulation results is shown in Fig. 5. Pearson correlation analysis proved that there was significant linear relationship between the measured and simulated results (Table 3 ). Hence, Radiance-based simulation is reliable to study daylighting performances of various internal light shelves under different tropical sky conditions. Among all the different sky conditions, simulation under overcast sky gave the highest correlation with the measured results. Simulation under intermediate sky without DSL (noon time) showed lowest correlation.

The findings indicated that various sky conditions gave different daylight penetration patterns. In overall, all the sky conditions gave extremely high WPI $(>1,000$ $1 \mathrm{x})$ at the area near to external window even with reflective glazing. Intermediate sky with DSL yielded the highest WPI. The experiment evidenced that the Base Case design without any shading device, which is the common design of contemporary high-rise offices, will result critical glare and thermal problems.

Previous research by Shahriar and Mohit (2007) in tropical climate stated that the depth of daylighting zone for $300 \mathrm{~lx}$ WPI was $3.5 \mathrm{~m}$. This study demonstrated that the effective daylighting depth (>300 lx) in tropical sky can be as deep as $7.2 \mathrm{~m}$ even under overcast sky with clear glazing (VT 75\%). Although the commonly used rule of thumb for effective daylight depth is 2.5 times height of the window from work plane $(2.5 \mathrm{H})$, this study proved that the effective daylight depth in tropical climate can be as much as $3.8 \mathrm{H}$.

Light shelf had successfully improved the daylight uniformity while still allowing sufficient daylight level for energy saving and visual comfort. The findings showed that light shelf was most effective during overcast day and intermediate day with DSL on East orientation. The design of light shelf shall respond to the presence of DSL and sun angle. Dynamic control of the light shelf is needed as sky conditions change dynamically. The recommended light shelf for various skies are summarised in Table 4.

From the recommendations, dynamic internal light shelf was developed to respond to different sky conditions. In the morning (with DSL facing east) under intermediate sky, configuration of LS 4 is employed. When the Sun angle is low under intermediate sky with DSL during afternoon, light shelf facing West orientation will be transformed into LS 3 configuration (Fig. 6). This kind of adjustment can be automated according to the time as the Sun angles change.

Illuminance sensor is needed in order to detect the sky conditions. When there is no DSL and $E_{G}$ is below $20,000 \mathrm{~lx}$, the light shelf shall transform to LS 2 which suit the overcast sky condition. The proposed dynamic internal light shelf is able to achieve the optimum daylighting performance by reflecting the daylight into the deeper room area while blocking the DSL to avoid glare and thermal problems.

Table 3. Pearson correlation between measurement and simulation resutls for various sky conditions

\begin{tabular}{llll}
\hline Sky condition & Pearson correlation & Sig. (2-tailed) & $\mathrm{N}$ \\
\hline Intermediate with DSL from east (morning) & $0.952^{* *}$ & 0.000 & 10 \\
Intermediate without DSL (noon) & $0.809^{* *}$ & 0.005 & 10 \\
Intermediate with DSL from west (afternoon) & $0.937^{* *}$ & 0.000 & 10 \\
Overcast & $0.984^{* *}$ & 0.000 & 10 \\
\hline
\end{tabular}


Table 4. Summary of optimum cases and daylight performances according to measurement

\begin{tabular}{|c|c|c|c|c|c|c|c|}
\hline \multirow[b]{3}{*}{ Sky condition } & \multicolumn{7}{|c|}{ Performance quantity (DR/DF, \%) } \\
\hline & \multirow[b]{2}{*}{ Optimum case } & \multicolumn{2}{|c|}{ Clear glazing } & \multicolumn{2}{|c|}{ Tinted glazing } & \multicolumn{2}{|c|}{ Reflective glazing } \\
\hline & & Max & Min & Max & Min & Max & Min \\
\hline Intermediate with DSL from east & LS 4 & 14.25 & 3.82 & 9.50 & 2.55 & 4.75 & 1.27 \\
\hline Intermediate without DSL & LS 3 & 2.87 & 0.78 & 1.91 & 0.52 & 0.96 & 0.26 \\
\hline Intermediate with DSL from west & LS 3 & 8.95 & 1.64 & 5.96 & 1.09 & 2.98 & 0.55 \\
\hline Overcast & LS 2 & 6.98 & 1.29 & 4.65 & 0.86 & 2.33 & 0.43 \\
\hline
\end{tabular}

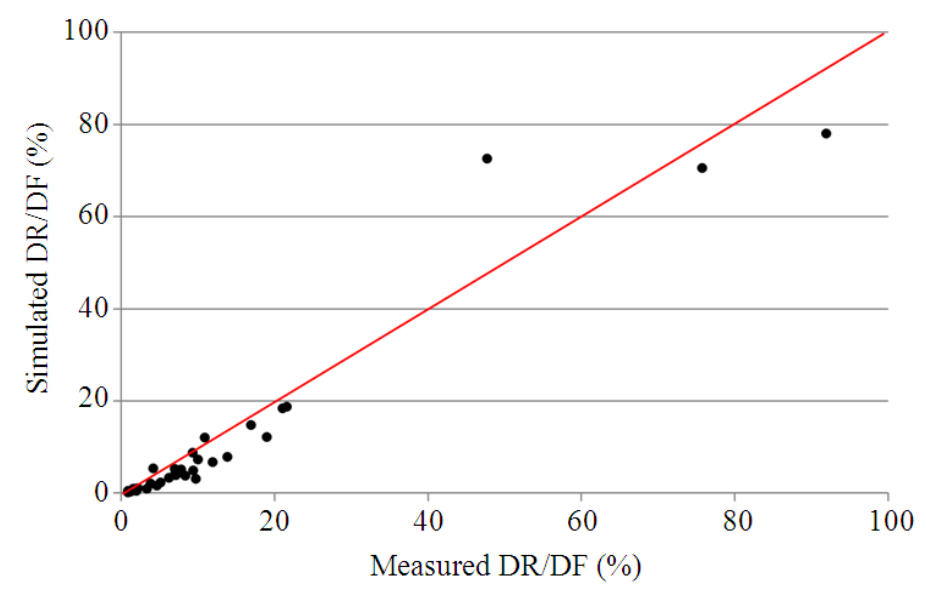

Fig. 5. Measured and simulated DR or DF

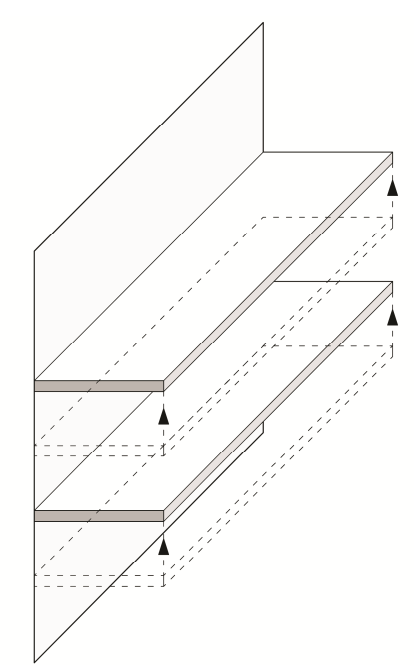

Fig. 6. Dynamic light shelf transforming from LS 4 to L3

\section{CONCLUSION}

Tropical daylighting performances for different orientations and sky conditions vary significantly. From both the measurement and simulation, the results evidenced that the presence of DSL determines the effectiveness of light shelf. Thus, the design of light shelf shall be flexible or adjustable to response to the various sky conditions in tropical climate. Dynamic internal light shelf was proposed for effective daylight and solar control in tropical climate.

This study focuses on the daylighting performance of light shelves for visual comfort by the measure of WPI (quantity). By shading DSL, it will also contribute to achieving thermal comfort among the office users. Nevertheless, further research is needed on thermal performances of the proposed light shelf designs as tropical daylighting is always associated with intensive solar radiation and heat gain.

\section{ACKNOWLEDGEMENT}

This research is funded by Universiti Teknologi Malaysia (UTM), Ministry of Education (MOE) through Research University Grant (GUP), Vote 07H36, titled "Dynamic Shading as Daylight and Solar Control for High-rise Office in Tropical Climate". 


\section{REFERENCES}

Ahmed, Z.A., K. Sopian, M.Y.H. Othman and Z.Z. Abidin, 2002. The Availability of daylight from tropical Skies. A case study Malaysia renewable Energy, 25: 21-30. DOI: 10.1016/S09601481(00)00209-3

DSM, 2007. MS 1525: 2007. Malaysian Standard. Code practice energy efficiency use renewable energy non-residential Buildings. Department of Standards Malaysia.

Djamila, H., C.C. Ming and S. Kumaresan, 2011. Estimation of exterior vertical daylight for the humid tropic of kota kinabalu city in east Malaysia. Renewable Energy, 36: 9-15. DOI: 10.1016/j.renene.2010.06.40.

Egan, M.D. and V. Olgyay, 2002. Architectural Lighting. 2nd Edn., McGraw-Hill Higher Education, New York, ISBN-10: 0-07-020587-6, pp: 436.

Lim, Y.W., 2013. Indoor environmental comfort in malaysian urban housing. Am. J. Environ. Sci., 9: 431-438. DOI:10.3844/ajessp.2013.431.438
Lim, Y.W., M.A. Hamdan and D.R. Ossen, 2010. Empirical validation of daylight simulation tool with physical model measurement. Am. J. Applied Sci., 7: 1412-1419. DOI: 10.3844/ajassp.2010.1426.1431

Lim, Y.W., M.A. Hamdan and D.R. Ossen, 2013. Internal shading for efficient tropical daylighting in existing high-rise open plan office. Indoor Built Environ., 22: 932-951. DOI: 10.1177/1420326X12463024

Lim, Y.W., M.K. Zin, M.A. Hamdan, D.R. Ossen and M.A. Aminatuzuhariah, 2012. Building facade design for daylighting quality in typical government office building. Build. Environ., 57: 194-204. DOI: 10.1016/j.buildenv.2012.04.015

Reinhart, C. and A. Fitz, 2006. Findings from a survey on the current use of daylight simulations in building design. Energy Build., 38: 824-835. DOI: 10.1016/j.enbuild.2006.03.012

Shahriar, A.N.M. and M.A. Mohit, 2007. Estimating depth of daylight zone and PSALI for side lit office spaces using the CIE standard general sky. Build. Environ., 42: 2850-2859. DOI: 10.1016/j.buildenv.2006.10.021 